\title{
El MUNDO VIRTUAL COMO NUEVO NÁRTEX PARA LA CATEQUESIS $^{1}$
}

THE VIRTUAL WORLD AS A NEW NARTHEX FOR CATECHESIS

\author{
Eduardo Valenzuela Magaña \\ Comisión Nacional de Catequesis \\ Conferencia Episcopal de Chile
}

\section{Resumen}

Este ensayo tiene como propósito problematizar la presencia de los medios digitales en la catequesis. Aunque son varias las implicaciones en este tema, uno llama la atención: la validez en los procesos de educación de la fe en ambientes virtuales. La pregunta es: el espacio catequístico virtual, jes un genuino espacio de encuentro con Dios y la comunidad? La respuesta es: sí, se puede dar una catequesis válida en estas circunstancias, aunque han de respetarse ciertas condiciones. Esto abre grandes posibilidades para evangelizar efectivamente en el mundo digital.

\section{Palabras clave}

Catequesis, mundo digital, redes sociales, rito, virtualidad

\section{Abstract}

The purpose of this essay is to problematize the presence of digital media in catechesis. Although there are several implications on this issue, one draws attention: the validity in the processes of faith education in virtual environments. The question is: Is the virtual catechetical space, a genuine space of encounter with God and the community? The answer is: Yes, a valid catechesis can be given under these conditions, although certain conditions must be respected. This opens up great possibilities to effectively evangelize in the digital world.

\section{KeYWORDS}

Catechesis, digital world, social networks, ritual, virtuality

1 Artículo inédito base de la ponencia presentada por el autor en el Congreso de Educación Religiosa "Diálogos Académicos sobre Catequesis 2021", organizado por el Instituto "Escuela de la Fe" de la Universidad Finis Terrae y otras entidades. Revisar en https:// www.youtube.com/watch? v=-jsKta86DPY

eduvama@gmail.com 


\section{INTRODUCCIÓN}

En este tiempo de pandemia a nivel mundial, la educación en general y la catequesis como acción educativa dentro del ámbito eclesial, se han realizado preferentemente utilizando medios digitales, con el fin de evitar el contacto directo entre las personas y con ello la transmisión del virus Covid-19. Para este efecto, el recurso principal son las redes sociales y una serie de plataformas educativas disponibles en la web. Ha sido un desafío complejo a nivel práctico, porque los catequistas no estaban preparados para realizar su tarea habitual usando internet. Más allá del conocimiento técnico escaso, el problema es que muchos catequistas han supuesto que se trata de digitalizar los textos tradicionales de catequesis y usar instrumentos tecnológicos en vez de papel. En cambio, el objetivo sigue siendo ofrecer experiencias de fe y no solamente "pasar" temas por internet (DC, \#371). En segundo término, está el desafío que se genera a nivel conceptual al hablar de "catequesis virtual". La misma expresión "virtual" es interpretada como referencia a algo no real; esto hace que surjan preguntas acerca de la "validez" de hacer catequesis por este medio y, aún más complejo, de lo real o no de un encuentro de catequesis de este tipo.

$\mathrm{Al}$ abordar este problema, el Directorio para la Catequesis incurre en una contradicción evidente al decir que "La realidad virtual no puede remplazar la realidad espiritual, sacramental y eclesial vivida en el encuentro directo con las personas... Para testimoniar el Evangelio, se requiere pues una comunicación auténtica, resultado de una comunicación real entre las personas" (DC, \#217). Esta afirmación se realiza en el documento solo unos párrafos después de señalar que las tecnologías de redes modernas son interesantes y útiles porque permiten la interacción (DC, \#214); y más adelante insiste en ello cuando se valora la relación intersubjetiva que se produce en las redes sociales (DC, \#369). ¿Puede señalarse que algo es valioso en el ámbito de las relaciones personales y, al mismo tiempo, que dicha relación no es real? Esa ambigüedad debe ser resuelta, porque 
todo indica que la catequesis virtual ha llegado para quedarse en la práctica catequética en alguna de sus versiones: completamente en línea o semipresencial. Frente a esta discusión existen dos posturas. La primera es que una sesión de catequesis no "presencial", sino "a distancia" por internet, no es "virtual", sino real. Tan real como la que se hace en una sala de la parroquia. Otros, en cambio, piensan que nunca podrá normalizarse la catequesis virtual y que esta situación es transitoria porque permite resultados limitados.

Este artículo tiene por objetivo abordar conceptualmente este problema con el fin de valorar el espacio catequístico virtual como una instancia genuina de encuentro con Dios y la comunidad. Para hacerlo, hablaremos en primer lugar acerca de lo que es un espacio sagrado y en qué sentido una sala de catequesis también lo es. Posteriormente, saldremos del espacio físico para entender cómo la ritualidad logra sacralizar el tiempo, que es eje característico de lo virtual, para convertirlo en un espacio habitable. Explicaremos en qué sentido la catequesis se basa en una pedagogía ritual que está dada por los distintos momentos del encuentro catequístico. La ritualidad será la forma cómo lo virtual se convierte en un nuevo nártex para la catequesis actual.

El enfoque del tratamiento excede lo puramente catequístico y transita por lo antropológico y filosófico, en donde encontramos herramientas para dilucidar la reflexión.

\section{Espacio y hecho CATEquístico}

El Directorio para la Catequesis (DC, \#222) señala que "los espacios para la catequesis son lugares a través de los cuales la comunidad expresa su forma de evangelizar. En el contexto actual, se hace necesario saber la especificidad de esos lugares para la catequesis, como instrumentos de proclamación y educación de relaciones humanas". Esto que señala el Directorio es aún más necesario cuando parte importante de la acción catequística en el contexto de la pandemia que está sufriendo 
la humanidad se realiza por medios virtuales, es decir, utilizando plataformas de internet que permiten la transmisión de videos y la interacción entre los participantes de modo sincrónico. ¿Es posible pensar que esta forma de catequesis se constituya en un modo no solamente habitual, sino que completamente válido para realizar procesos de educación de la fe en el futuro post pandemia? Existen voces categóricas que niegan esta posibilidad y que afirman que la catequesis virtual nunca podrá reemplazar a la catequesis presencial; que la catequesis siempre deberá hacerse cara a cara, en una sala y preferentemente dentro de un recinto parroquial, favoreciendo el "contacto personal" (DC, \#219), el cual -se entiende- no logra ser pleno en el ámbito digital. Sin embargo, el hecho es que la catequesis digital ya está instalada, se realiza y probablemente se seguirá realizando. Por lo tanto, es urgente reflexionar acerca de qué es lo específico de los lugares donde realizamos la catequesis y cuál es el lugar que le corresponde hoy a lo virtual en el devenir de la evangelización de la Iglesia. Nuestro acercamiento a este tema se abrirá paso a partir de los conceptos de "espacio educativo", que por extensión será para nosotros el "espacio catequético"; y al concepto de "hecho educativo", que en nuestro ámbito adquiere un sentido absolutamente distinto en lo que llamamos "hecho catequístico".

Todo hecho educativo formal se da en un espacio y tiempo determinados (Villarreal et al., 2019) y tiene por objetivo que el niño o el joven adquiera los códigos culturales y sociales que le permitirán desarrollarse como persona, además de interpretar y relacionarse adecuadamente con su entorno, con los demás, con el trabajo y con su dimensión espiritual. Este hecho acontece dentro de la escuela en general, pero específicamente dentro de una sala de clases. Por cierto, todo el entorno educativo debe permitir educar: la multicancha, el casino, el patio, la biblioteca y los baños; pero la intencionalidad educativa se da de modo preeminente en la sala de clases. Este es el lugar donde transcurre la mayor parte del tiempo escolar de un alumno; es un espacio donde se comparte, se escucha, se reflexiona, se aprende a convivir, a callar, a respetar, a memorizar, a ejercitar y 
a hacer, en definitiva, todas las tareas y acciones que permiten a una persona educarse. Ya la misma sala de clases, su disposición espacial, indica una manera de concebir la relación educativa. Si una sala está en posición de herradura, puede favorecer el diálogo mejor que una sala dispuesta en forma unidireccional hacia delante; si en una sala el profesor se ubica en una tarima superior, eso igualmente dice algo sobre la relación educativa que acontece en ese lugar.

La catequesis también tiene su origen en un hecho, pero de una naturaleza distinta. Ese hecho se denomina hecho catequistico (Borello, 2005, p. 27ss) y se fundamenta en la acción de Dios que busca incesantemente encontrarse con el ser humano, el cual puede abrir su corazón y dar una respuesta de aceptación a esa manifestación por medio de su fe. El hecho catequístico no es solamente un hecho educativo que puede ser comprendido desde la sociología, la sicología o la pedagogía; sino que tiene además un carácter teológico y solo puede ser comprendido a cabalidad desde esa perspectiva. El catequista, por tanto, es aquel que facilita ese encuentro de voluntades que se da en el ámbito de la Gracia infinita de Dios y la libertad del ser humano, como una verdadera manifestación de lo sagrado en la historia humana. La catequesis dispone al ser humano para profundizar su experiencia religiosa con la cual interpreta en profundidad la propia vida (Alberich, 1991) a fin de asignarle sentido.

El hecho catequístico, que hemos descrito brevemente, se da en un espacio y tiempo determinados, que se disponen intencionadamente para este propósito; es lo que denominamos espacio catequístico. La sala de catequesis, como elemento del sistema catequístico, no ha sido suficientemente perfilada para entender cuál es su especificidad respecto de cualquier otro espacio posible ¿Existen salas de catequesis que permitan mejor que otras llevar a cabo un proceso educación de la fe? ¿Hay lugares donde nunca sería posible hacer un encuentro de catequesis? ¿Qué es lo característico de una sala de catequesis? Su decoración, la presencia de imágenes religiosas, la distribución de las sillas, su entorno, la cercanía física con el templo, la posibilidad que permite el espacio de entrar en contacto con otros, la inclusión de 
ciertos signos específicamente religiosos, como un cirio o una cruz, por ejemplo. Para el ámbito de la liturgia, en cambio, el lugar de la celebración está claramente definido con elementos fundamentales: el altar, la sede, la nave, el presbiterio, etc., de modo tal que podemos celebrar la eucaristía en una catedral medieval o con jóvenes al pie de una montańa; y en ambos casos permanece intacta la distinción entre el espacio sagrado y el profano. Si fuéramos capaces de distinguir del mismo modo esos elementos para una sala de catequesis, ¿podrían estos ser incorporados en un sistema de educación catequística basado en plataformas de internet? ¿Es posible una hierofanía de contenido catequístico en lo digital? ¿Dónde reside lo sagrado en el ciberespacio cuando hablamos de educar la fe de otro? ¿Puede lo digital ser un nuevo nártex para quienes quieren educar su fe hoy? Estas y otras preguntas son claves para reflexionar acerca del valor relativo de lo virtual en la catequesis.

\section{CATEquesis y ESPACIO SAGRAdo}

Para un hombre religioso o de fe, no todos los lugares son iguales: "el espacio no es homogéneo", dirá Mircea Eliade (1981, p. 15-40), porque existen porciones de este que son cualitativamente diferentes de otras a las que denominamos "espacios sagrados". En estos lugares, al igual que Moisés lo hizo, hay que "quitarse el calzado" (Ex 2:5), porque en ellos está presente Dios y esto los hace distintos de la insignificancia que tienen los otros espacios comunes en el mundo. La existencia de un espacio sagrado da al creyente un "punto fijo" con el cual orientarse en la homogeneidad desordenada que percibe alrededor. La pertenencia a este espacio permite al ser humano poder narrar su entorno y comprenderlo desde un punto de vista trascendente. Por el contrario, cuando se debilita la experiencia religiosa, tal como ocurre hoy, el mundo se fragmenta en una infinidad de lugares inconexos, que ponen al ser humano actual en estado de extravío. Por esta 
razón, ver destruido el propio espacio sagrado no es un problema de materialidad, sino de sentido.

Pese a esta condición de desapego a lo sagrado, Mircea Eliade revaloriza el hecho de que en el espacio profano también existan "lugares" no homogéneos o diferenciados que están delimitados por la experiencia de cada persona y que los hacen cualitativamente diferentes a otros: la casa donde se nació, el barrio donde se crece, el lugar donde se iba a vacacionar de pequeños, etc.; todos lugares donde se experimentaron vivencias que establecieron vínculos de afecto con las personas. Son los "lugares santos" de la propia historia personal; lugares que permiten el arraigo a la existencia y que limitan ciertamente con el espacio sagrado trascendental, constituyéndose en pasos de acercamiento a este.

Eliade, usa la imagen de la "iglesia en una ciudad moderna" para ejemplificar el límite entre lo sagrado y lo profano. Entre ambos existe un umbral que es una frontera y que divide ambos mundos y que asimismo los conecta; constituyéndose de este modo literalmente en la puerta por la que se transita desde el espacio profano al sagrado o en sentido contrario. Esta entidad permite distinguir el espacio sagrado del profano, ya sea que estemos en una catedral antigua o en una capilla de oración que jóvenes han construido utilizando ramas y cordeles, en medio del bosque. En ambos casos existe un efecto umbral que limita lo profano de lo sagrado. Umbral o puerta, que muestra la continuidad del espacio y que actúa a la vez como símbolo y vehículo de tránsito. 


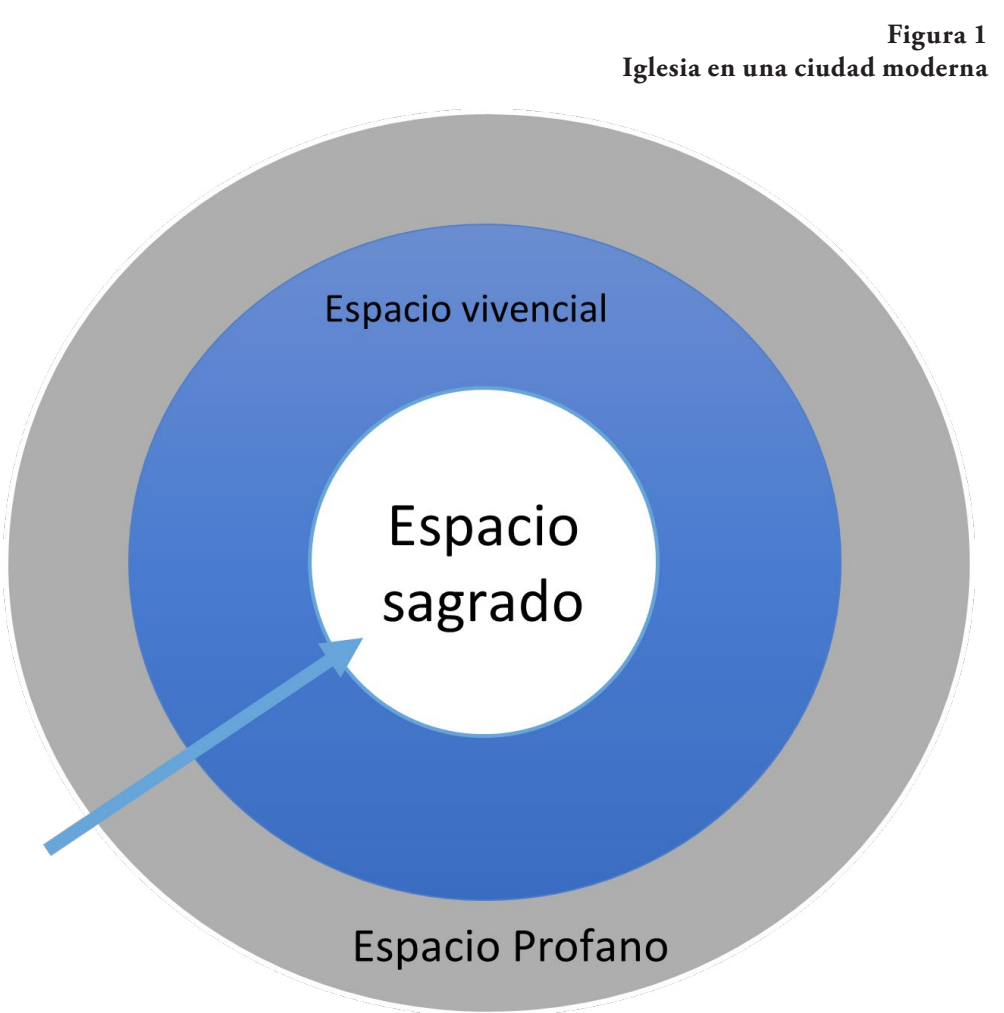

Fuente: elaboración propia

La catequesis es, en cierto sentido, una puerta que se abre hacia lo alto para que Dios pueda irrumpir en el mundo, haciendo de ese espacio un lugar sagrado. Es, utilizando una imagen del Génesis, una puerta al cielo (Gn 28:12-19) en cuanto es el umbral en donde acontece el encuentro entre Dios y el ser humano (hecho catequístico). En cada catequesis Dios vuelve a entrar al mundo, y el hombre, por esa misma puerta, sale a su encuentro. La catequesis es el lugar donde "arde la zarza sin quemarse", la montańa y desierto, donde Dios se encuentra íntimamente con el ser humano. La catequesis es el Tabor, donde cada hombre experimenta la manifestación de Dios que lo llama a seguir a su Hijo. 
La idea de que también exista un espacio sagrado en una catequesis virtual es posible en la medida en que quienes participan del acontecimiento definan que ese espacio es para encontrarse con Dios y que acepten que eso es posible. El límite de lo sagrado no se traza solamente en la frontera del lugar físico o del acontecimiento sobrenatural, sino sobre todo en la imaginación del grupo (Flores, 2007, p. 42) o, mejor dicho, en la intencionalidad de quienes son convocados a participar: "Donde dos o tres se reúnan en mi nombre, yo estoy en medio de ellos" (Mt 18:20). Si quienes se reúnen en una catequesis utilizando un medio digital lo hacen con la intención explícita de encontrarse con Jesucristo, podemos confiar en que Él está en medio de ellos, en la misma red, y en ese sentido ese espacio digital puede constituirse en un lugar sagrado.

Por último, hay que señalar que el espacio virtual o "ciberespacio" debemos entenderlo de modo análogo a lo que conocemos como espacio geográfico. Todo espacio es tal si puede ser habitado y nos permite interrelacionarnos con otros. Bajo esta definición, el espacio virtual es un espacio de la misma categoría que el espacio físico, pero con una naturaleza distinta. Siendo así, debemos preguntarnos si es posible "demarcar" el ciberespacio sagrado del ciberespacio profano. ¿Cómo establecer el umbral entre ambos? Para responder a esta pregunta necesitamos profundizar el concepto de rito y asociarlo al de espacio sagrado.

\section{LA FUNCIÓN DE LA RITUALIDAD EN EL ENCUENTRO CATEQUÍSTICO}

Hemos señalado que el espacio sagrado es un punto de anclaje que permite resolver la homogeneidad espacial. Del mismo modo, el rito cumple esa función, pero con respecto al tiempo profano, el cual también es homogéneo y no diferenciado. Para el hombre actual, el tiempo carece de un armazón firme y se transforma en un flujo inconsistente, porque no existe un punto de anclaje para narrarlo. 
Estas expresiones pertenecen al filósofo surcoreano Byung Chul Han, que en su libro La desaparición de los rituales (2020) realiza una defensa de la ritualidad en un mundo en el cual existe un vacío simbólico, sin imágenes ni metáforas generadoras de sentido y fundadoras de comunidad. Este autor parte definiendo los ritos como "acciones simbólicas". Para entender esta definición, debemos entender qué es un símbolo.

El concepto de símbolo remite a la idea de una contraseña entre gente hospitalaria, que servía para reconocerse usando una tablilla de arcilla que se partía en dos y que se entregaba a ambas personas. El acto de reconocerse implica volver a lo que ya conocimos o a lo que nos es familiar. Esa es la función que cumplen los rituales: estabilizan la vida gracias a su repetición, que nos remite a lo mismo que conocemos, proporcionando "mismidad", dirá el autor citando a Arendt; y con ello duración y sentido.

Los rituales hacen del mundo un lugar fiable. "Son en el tiempo lo que una vivienda es en el espacio” (Chul Han, 2020, p. 6). Una casa, la reconocemos como nuestra casa porque en ella están nuestras cosas: el comedor, nuestros sillones, plantas, ollas, etc. Los rituales "son en la vida lo que en el espacio son las cosas” (p. 7), le dan identidad a la existencia y la estabilizan porque nos sitúan en un mundo que se convierte en "nuestro" mundo.

La repetición es algo esencial en los rituales. Repetir no es igual a la monotonía de la rutina, ni tampoco puramente recordar, ya que esta acción se dirige hacia el pasado. En cambio, dice Chul Han, en el ritual se recuerda, pero "hacia delante". En la repetición, "pasado y futuro se fusionan en un presente vivo" (Chul Han, 2020, p. 11), el cual se vuelve intenso, aunque sea discreto y cotidiano en su contenido. Las repeticiones dan estabilidad a la vida y su rasgo esencial es su capacidad para instalarnos en un hogar en el cual podemos entrar confiadamente.

Por último, los ritos nos vinculan a los demás porque crean ejes de resonancia que construyen relaciones verticales con lo trascendente, horizontales con la comunidad social y diagonales con las cosas. En 
el rito, no se requiere cultivar la empatía, dice Chul Han, porque el contacto con el otro se produce por la resonancia del mismo rito que conecta persona a persona y nos transforma en comunidad.

En definitiva, el rito cumple con la función de superar la homogeneidad e insignificancia del tiempo, al hacer que en ese mismo eje se construya un hogar habitable y distinto a todo lo demás. ¿Cómo hacemos que el día de cumpleaños o el de aniversario de un matrimonio sea algo distinto y no solamente una vuelta más de la tierra alrededor del sol? La respuesta es que logramos diferenciarlo del resto de los días porque realizamos ritos: saludos, tortas, cantos, regalos, etc. Esas acciones simbólicas logran hacer discontinua la monotonía de cada día, diferenciando ese tiempo de cualquier otro.

El rito o lo ritual es valorado como una importante herramienta pedagógica. Quienes lo han estudiado en este sentido, lo definen operativamente, lo que nos permite implementarlo en procesos educativos: "El ritual es una secuencia conductual que está estructurada o pautada, es rítmica y repetitiva, tiende a recurrir de la misma o casi de la misma manera con bastante regularidad, actúa para sincronizar procesos afectivos, perceptivos, cognitivos y motores en el sistema nervioso central de los participantes y, de manera más particular, sincroniza estos procesos entre varios individuos participantes" (Cuéllar, 2007).

Valiéndonos de esta definición, podemos diferenciar un encuentro de catequesis virtual de las otras reuniones que una persona tiene durante el día, como las que establece por estar en modo de teletrabajo, por ejemplo. Si la catequesis virtual está bien diseñada, deberá explicitar el umbral a lo sagrado valiéndose de la ritualidad propia del encuentro catequístico. Hay que preguntarse entonces si tenemos claridad acerca de los ritos propios de un encuentro de catequesis. La forma de saludar, de leer la Biblia, de encender una vela, hacer silencio y orar en comunidad son parte de esa ritualidad. Los mismos momentos que repetimos en cada encuentro de catequesis: la experiencia, el anuncio, la respuesta y el compromiso son los momentos del rito. Hacemos lo mismo siempre, como una secuencia estándar que no es monotonía 
pedagógica, sino ritualidad educativa que nos conecta. Muchas veces se critica el uso de textos catequísticos, porque tienden a monotonizar el proceso y el catequista se vuelve dependiente de ellos. Sin duda, eso es posible y representa un problema. Sin embargo, un texto de catequesis ayuda a la ritualización del encuentro al imponer cierto ritmo y método de desarrollo. En cualquier caso, este material será insuficiente si el catequista no ejecuta de modo ritual los encuentros que ha planificado. La Biblia no se lee en catequesis, sino que se proclama. Los catequizandos no rezan y cantan, sino que celebran lo aprendido. Convendrá, por lo tanto, dejar la idea de que "nosotros hacemos catequesis en grupo" para reemplazarla definitivamente por la expresión "nosotros celebramos la catequesis en comunidad".

\section{Resumen DE LOS CONCEPTOS EXPUESTOS}

Sinteticemos todo lo expresado hasta el momento por medio del siguiente esquema:

Figura 2 Síntesis de conceptos

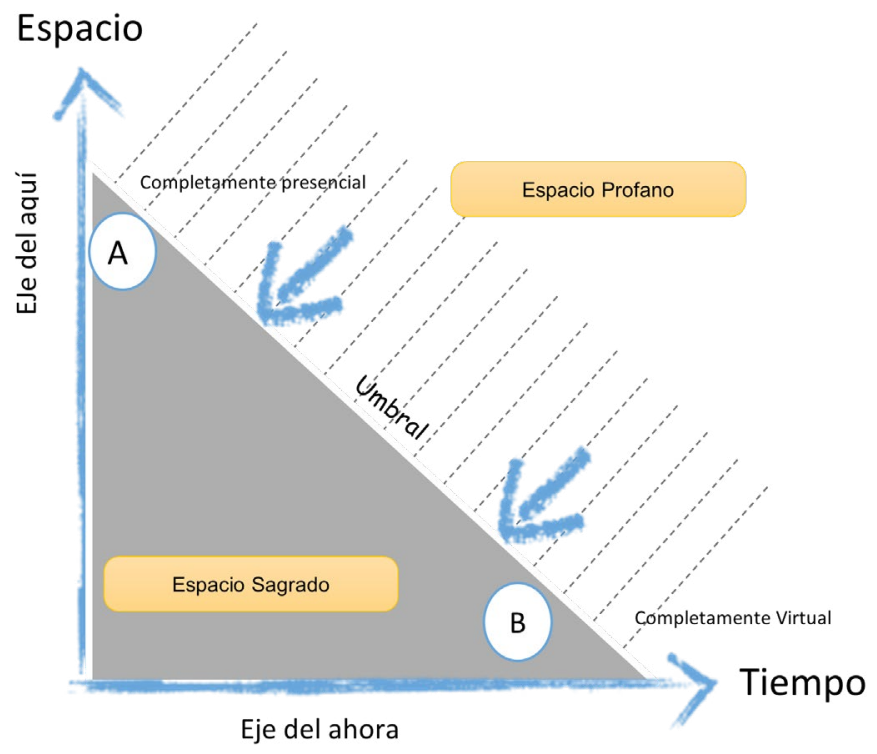

Fuente: elaboración propia 
El hecho catequístico se da en un espacio y tiempo determinados, es decir, en un aquí y ahora específicos. En nuestro esquema, existe un "eje del aquî" y un "eje del ahora". Si nos movemos por el eje del aquí, en el sector $A$, nos encontramos con una catequesis completamente presencial. Acá la sala de catequesis, como espacio sagrado, establece un umbral convirtiéndose en nártex. Recordemos que era un espacio situado entre los pasillos y la fachada principal de la basílica destinado a albergar penitentes y catecúmenos, el cual estaba decorado con escenas bíblicas u otras imágenes de los misterios de la fe y que se constituyó en el espacio propio de la catequesis (DC, \#221). El Directorio suma otras características con respecto al espacio actual: debe ser acogedor y bien cuidado, para que se perciba un clima de familiaridad que fomente una participación alegre en las actividades comunitarias; no una sala de clases escolar, sino un espacio adecuado al carácter de encuentro que tiene la catequesis.

Por otra parte, si nos movemos por el eje del ahora, que tiene escala de tiempo, encontramos en su extremo el sector B. En esta coordenada estamos frente a una catequesis completamente virtual. Acá el espacio físico, no es que deje de existir, porque no existe el "no espacio", sino que no es relevante y la acción se deslocaliza, para relevar el "ahora". Es un tiempo absoluto que no tiene relación con el tiempo histórico. El tiempo real virtual es independiente de la propia geografía, porque es relativo a una zona horaria (GMT, por ejemplo). "Ya no existe el aquí, todo es ahora" (Virilo, citado por Peña, 2010, p. 123). Acá necesitamos construir otro tipo de nártex, esta vez de naturaleza ritual; es decir, si queremos diferenciar el tiempo profano del trabajo en línea que hace una persona en el día o de las clases virtuales de los nińos, debemos establecer un umbral esta vez dado por el rito tal como lo hemos explicado anteriormente.

En definitiva, lo presencial es puro espacio y corporalidad; lo virtual es tiempo absoluto. Lo presencial constituye umbral modificando el espacio, y lo virtual constituye umbral ritualizando el tiempo para hacerlo hogar. 
Eduardo Valenzuela Magaña | El mundo virtual como nuevo nártex para LA CATEQUesis

\section{ENTENDER LA PRESENCIALIdAd EN LA CATEQUESIS VIRTUAL}

Hasta el momento hemos discutido el problema del espacio catequístico, tanto el físico como el virtual, y cómo es posible que acontezca el hecho catequístico en ambos. En segundo lugar, definimos cómo establecer el umbral que delimita el tiempo y el espacio profano del sagrado, por medio del símbolo y la ritualidad, respectivamente. Sin embargo, todo esto no es suficiente si no aceptamos que las personas nos hacemos presentes de manera genuina también en una actividad virtual, es decir, si no estamos dispuestos a conceder sin duda alguna que la persona que vemos de este lado de la pantalla es la misma que está del otro lado. En este último apartado pretendemos discutir brevemente este problema, defendiendo la presencia real en lo virtual desde dos perspectivas: la cognitiva y la vital.

Dar un salto hacia la virtualidad presenta numerosos problemas para quienes creen que es la presencialidad física la que da sacralidad y legitimidad a un rito específico (Flores, 2007, p. 44). En este tiempo, en el cual las comunidades religiosas han debido permanecer en confinamiento, este problema ha sido especialmente relevante, pues definir el espacio sagrado y los rituales religiosos de modo ajeno a los espacios físicos constituye una gran dificultad conceptual y vivencial en lo religioso. Quienes han diseñado lo que se ha llamado "iglesias virtuales" o se atrevieron en un comienzo a cruzar la frontera para realizar "misas online", debieron hacerlo con el fin de permitir la continuidad de la ritualidad o la "ciberritualidad", dejando de lado todo tipo de cuestionamientos. Se ha tratado de replicar o acercar, en la medida de lo posible, la experiencia de una iglesia física, de modo tal que se exige que detrás de lo que está ocurriendo en la "iglesia virtual" de la pantalla exista al mismo tiempo una "iglesia real” ubicada en el mundo físico donde está ocurriendo lo verdadero.

En las noticias internacionales, se hizo conocido el gesto de un párroco europeo quien decidió poner fotografías de los fieles de la comunidad en las bancas de la nave de la iglesia, mientras celebraba 
la eucaristía. Al mismo tiempo, los "fieles reales" participaban de la celebración en sus casas viendo la transmisión por internet. Este episodio deja en evidencia que lo virtual no tiene para muchos una entidad independiente de lo físico, que es lo "verdaderamente real". Por esta razón, se espera que toda acción ritual digital deba ser considerada provisoria por ser imperfecta, no plena, o puramente aparente. No se puede sino observar un evidente dualismo en estas expresiones. Esta idea de que lo virtual referencia a lo real del mundo físico es la nueva "alegoría de la caverna", pero en sentido opuesto: el mundo de las ideas es lo físico y "las sombras" están en la pantalla.

Lo mismo han experimentado quienes han tenido que hacer "catequesis virtuales". Para muchos, la idea de "virtual" implica algo no real, aparente o no completamente en serio. El mismo Directorio para la Catequesis plantea este problema cuando establece limitaciones a las catequesis digitales, porque no permiten "una interacción auténtica, resultado de una interacción real entre las personas” (DC, \#217), aunque antes exprese que las "formas de comunicación digital, en cambio, ofrecen mayores posibilidades ya que están abiertas a la interacción” (DC, \#215). ¿En qué creemos, entonces? ¿Existe o no interacción real en lo digital? Si la respuesta es no, ¿qué sentido tiene promover el uso de la tecnología si la interacción no es genuina? Debemos abordar el problema y establecer en qué medida una interacción mediada por una tecnología es o no una interacción auténtica o real.

Quienes tenemos hijos en la edad escolar los hemos visto mudar en este tiempo su forma de participar en las clases usando plataformas digitales tales como Classroom y Meet. Al comenzar cada sesión, los profesores revisan la asistencia del curso y cada niño responde "Presente". Yo, que estoy al lado de mi hijo cuando responde, doy fe de que él está efectivamente presente, pero su profesor no requiere de mi confirmación para saberlo (además del hecho de que se armaría un bucle de confirmación entre mi hijo y yo), porque sabe que efectivamente podemos estar presentes plenamente en una actividad educativa que se realiza de modo virtual. Ciertamente "el ingenio humano" puede engańar al interlocutor. ¿Cómo? Teniendo la cámara 
apagada puedo irme del lugar o, peor aún como lo hizo un político argentino, que engañó a sus colegas cuando puso una foto suya frente a la pantalla para hacer creer que participaba atentamente de la discusión legislativa.

Para defender la presencialidad en lo virtual usaremos dos argumentos. El primero es el argumento cognitivo. Para esta posición, no existe duda alguna de que la interacción en línea es una experiencia tan real como la que percibimos en el mundo físico. ¿¿Por qué? Porque en ambos casos la interacción es posible debido a que el cerebro actúa interpretando lo que captan los sentidos: imágenes y sonidos, en este caso; y esta interpretación es la base de interacción con los otros. Este proceso es lo que en ciencias cognitivas se define como "percepción". Desde una perspectiva cognitiva, "la percepción tiene una función de interpretación de los datos sensoriales y supone una actividad de procesamiento de la información" (Houdé et al., 2003). Por lo tanto, si el conocimiento lo construye el sujeto cognoscente, a partir de la percepción, podemos afirmar que la experiencia en línea es tan real (o si se quiere tan irreal) como la experiencia fuera de línea.

El sociólogo Manuel Castells señala que la tecnología transforma de manera fundamental no solo el carácter de la comunicación, sino que da lugar a la emergencia de una cultura de la virtualidad real. Asimismo, afirma que "la realidad, tal como se experimenta, siempre ha sido virtual, porque siempre se percibe a través de símbolos" (Peña, 2010, p. 121), los cuales son interpretados por nuestro aparato cognitivo.

El segundo argumento es el que denominaremos argumento vital. Los catequistas que en este tiempo han realizado catequesis virtuales con su grupo no tienen duda de que efectivamente se han encontrado con los catequizandos, que han compartido temas importantes de sus vidas y emociones genuinas, que han podido crecer en su experiencia comunitaria y de encuentro con el Señor. Todo esto ha sido una "interacción auténtica", una "interacción real entre personas", no una pura apariencia. Eso es una certeza que comparten, de acuerdo con su experiencia, tanto catequistas como catequizandos. Un amigo 
catequista y catequeta nos comparte su testimonio al respecto, que además nos sirve para comenzar a cerrar este apartado:

En una peregrinación hacia un lugar sagrado en un microbús o en un tren, que son espacios profanos, se produce un acontecimiento sagrado si los viajeros se ponen a rezar y a cantar a Dios y a los santos. Una sesión de catequesis no "presencial" sino "a distancia" por internet no es "virtual", sino real. Acabo de escuchar el testimonio de colegas que realizaron a distancia uno de sus habituales Encuentros con Cristo semestrales, esta vez con un cuarto medio del colegio, y estaban muy satisfechos del logro esperado y fue aún mejor de lo que esperaban. Yo enseño semanalmente Catequética Fundamental a los seminaristas vía Meet. Rezamos y cantamos al principio y al final de cada sesión, y los califico a cada uno por cada sesión en que contestan una pregunta por escrito que me envían a mi e-mail, con promedio cada semana cercano a la nota siete.

Además de verificar que estamos ante un buen profesor y catequista, sabemos que resulta imposible tratar de desmentir esta experiencia; a no ser eso sí, que logremos descubrir que el catequista en realidad ha interactuado no con personas, sino con bots o con autómatas al estilo de los que describía Descartes en sus meditaciones.

\section{Conclusión}

Este documento ha tenido como objetivo responder a la pregunta acerca de la posibilidad de hacer del virtual un espacio genuinamente catequístico, donde se pueden realizar catequesis no solamente válidas, sino profundamente transformadoras para la vida de los catequizandos. La respuesta es categórica: sí, se puede. Sin embargo, para lograr este objetivo debemos tomar en cuenta al menos dos consideraciones.

Primera consideración: Se debe revalorizar y acentuar la dimensión ritual de la metodología catequística. Esto es fundamental para lograr que exista discontinuidad entre el tiempo dedicado a la catequesis y las otras actividades que se realizan vía online durante el día. El 
catequista debe manejar las pausas, los silencios, los gestos, la forma como lee y se escucha el Evangelio, tanto como permitir el tiempo para que este repercuta en el interior de las personas. La catequesis virtual debe acentuar el carácter celebrativo del proceso, destacando la liturgia pedagógica propia del método catequístico. No se hacen catequesis, sino que se celebran. Se trata, sobre todo, de hacer sentir la presencia del Señor que ha prometido estar con nosotros en todo lugar, si nos reunimos en su nombre (Mt 18:20). En este mismo punto existe un enorme desafío, porque no hemos profundizado la dimensión ritual de la pedagogía catequística, particularmente el lugar del lenguaje narrativo, que excede lo puramente bíblico y que es una clave fundamental en la catequesis actual (DC, \#207-208).

Segunda consideración: Se debe alentar la interacción constante de las personas durante la catequesis virtual, ya que esto ayuda a experimentar lo genuino del encuentro entre los participantes. Para lograrlo, lo primero es indicar que la catequesis requiere rostros para dialogar y reconocerse, así que la interacción debe hacerse, en la medida de lo posible, con la cámara encendida. La comunicación no verbal también es necesaria en un encuentro virtual y hay que favorecerla. Hoy, la tecnología está al alcance de las personas y se debe aprovechar al máximo. En segundo lugar, la catequesis no se puede convertir en una charla unidireccional dada por Zoom u otra plataforma, sino que la metodología debe permitir la interacción entre los miembros. Preguntas, debates, trabajos en pequeños grupos, juegos, desafíos, etc., son todas acciones posibles de realizar con los medios digitales y deben implementarse. El Directorio para la Catequesis nos recuerda que "las tecnologías de la información y la comunicación, las redes sociales, los dispositivos digitales fomentan los esfuerzos de colaboración, del trabajo en común, del intercambio de experiencias y del conocimiento mutuo" (DC, \#215).

Por último, hay que reconocer que estamos ante una oportunidad enorme para desarrollar la evangelización y la catequesis. Al vernos de alguna manera obligados a involucrarnos con el mundo digital, hemos encontrado un enorme potencial para que la catequesis logre 
"convertirse en una presencia evangelizadora en el continente digital" (DC, \#371). La "red" es sin duda el principal areópago moderno de los que tantas veces nos han hablado los últimos Papas y que nos ha transformado en lo que llamamos "aldea global". Este mundo conectado que miramos muchas veces con miedo, pero también con esperanza, debe recibir el anuncio del Evangelio que transforma la vida. Esa es la gran tarea de la catequesis para estos días.

\section{REFERENCIAS}

Alberich, E. (1991). La catequesis en la Iglesia. Elementos de catequética fundamental. Central Catequística Salesiana.

Borello, M. (2005). Catequética fundamental para educadores de la fe. EDEC.

Cuéllar Iborra, A. (2007). Más allá de la celebración. La metodología del ritual y sus aplicaciones en contextos de cambio, aprendizaje y desarrollo. En Primer Seminario de Pedagogía del Rito. Universidad Central de Chile.

Chul Han, B. (2020). La desaparición de los rituales. Herder.

Eliade, M. (1981). Lo sagrado y lo profano. Guadarrama/Punto Omega.

Flores, F. (2020). Espacialidad y religiosidad en tiempos de Covid 19: apuntes preliminares desde la geografía de las religiones. Espaço e Cultura, (47), 37-54. https://www.e-publicacoes.uerj.br/index. php/espacoecultura/article/view/54815

Houdé, O., Kayser, D., Koenig, O., Proust, J., Rastier, F. (2003). Percepción. En Diccionario de Ciencias Cognitivas. Neurociencia, Psicología, Inteligencia Artificial, Lingüistica, Filosofía. Amorrortu editores. 
Eduardo Valenzuela Magaña | El mundo virtual como nuevo nártex para LA CATEQUesis

Peña, J. A. (2010). La concepción filosófica de lo virtual en la educación virtual. Revista Colombiana de Educación, (58), 118-138. https:// doi.org/10.17227/01203916.639

Pontificio Consejo para la Promoción de la Nueva Evangelización (2020). Directorio para la Catequesis. CELAM.

Villarreal, M. A. y Gutiérrez, J. (2019). Espacios Educativos y Aprendizaje. Administración Federal de Servicios Educativos en el Distrito Federal, México. https://educrea.cl/espacios-educativosy-aprendizaje/

Fecha de recepción: 13 de mayo de 2021 Fecha de aceptación: 24 de mayo de 2021 